\title{
Induced Pluripotency of Mouse and Human Somatic Cells
}

\author{
N. MAHERALI*广 AND K. HochedLINGER* \\ *Massachusetts General Hospital Cancer Center and Center for Regenerative Medicine; \\ Harvard Stem Cell Institute; Department of Stem Cell and Regenerative Biology; Boston, Massachusetts 02114; \\ ${ }^{\dagger}$ Department of Molecular and Cellular Biology, Harvard University, Cambridge, Massachusetts 02138
}

\begin{abstract}
The identification of transcription factors to induce pluripotency directly in somatic cells has given researchers a unique platform on which to dissect the mechanisms underlying epigenetic reprogramming. In addition, induced pluripotent stem (iPS) cells have enabled the derivation of patient-specific cells for the study and potential treatment of a variety of diseases. Here, we discuss recent discoveries in the reprogramming field including work from our own laboratory.
\end{abstract}

Reprogramming denotes the experimentally induced dedifferentiation of somatic cells into pluripotent cells, and pluripotency defines the ability of cells to give rise to all embryonic cell types including the germ line. Two major aims of reprogramming research are to understand the underlying mechanims at a biochemical level and to generate custom-tailored cells for studying and treating degenerative diseases. Experiments in mice have shown that iPS cells can indeed alleviate the disease phenotypes of sickle cell anemia (Hanna et al. 2007) and Parkinson's disease (Wernig et al. 2008b). This, and the recent derivation of patient-specifc iPS cell lines from 11 different genetic disorders (Dimos et al. 2008; Park et al. 2008a), demonstrates the potential utility of reprogramming research in a therapeutic setting.

Several different approaches have been developed to study the reprogramming of somatic cells into pluripotent cells, including nuclear transfer (NT), cell fusion, and direct reprogramming (Fig. 1). During NT, the nucleus of a somatic cell is injected into an enucleated oocyte, which then develops into a cloned embryo. When transferred into a recipient female, the cloned embryo can develop into a live animal (so-called reproductive cloning) (Fig. 1A) (Wilmut et al. 1997; Wakayama et al. 1998). When explanted in vitro, NT-derived embryonic stem (ES) cells can be derived, which may be useful for custom-tailored cell therapy (so-called therapeutic cloning) (Rideout et al. 2002). The process of NT is extremely inefficient (on average, only $1-3 \%$ of cloned blastocysts develop to term), and many of the cloned animals are abnormal, likely due to faulty epigenetic reprogramming of the genome (Hochedlinger and Jaenisch 2002b). Interestingly, the derivation of ES cells from cloned blastocysts seems to select for fully reprogrammed cells because NT ES cells are molecularly and functionally indistinguishable from fertilization-derived ES cells, including their ability to give rise to entirely ES-cell-derived mice (Brambrink et al. 2006). Thus, the abnormalities seen in cloned animals should not impede the therapeutic use of NT technology. However, ethical and legal constraints surrounding NT make alternative approaches to reprogramming desirable. Moreover, NT does not provide sufficient amounts of material to biochemically dissect the process of reprogramming.
An alternative approach to studying reprogramming is cell fusion, which involves the fusion of somatic cells with ES cells, thus generating pluripotent hybrids in which the somatic genome acquires epigenetic marks of ES cells (Fig. 1B) (Tada et al. 2001; Cowan et al. 2005). Cell fusion is also quite inefficient, making it difficult to perform biochemical analyses. Nevertheless, cell fusion has been helpful in determining the effects of individual genes on reprogramming efficiency. For example, overexpression of the transcription factor Nanog in ES cells has been shown to result in an up to 200 -fold increase in the number of reprogrammed hybrids upon fusion with neural stem cells (NSCs) (Silva et al. 2006). Cell fusion is not a viable approach in cell therapy, however, because the genomes of two different individuals are combined in hybrid cells, resulting in tetraploid cells that are prone to chromosomal abnormalities (Fujiwara et al. 2005).

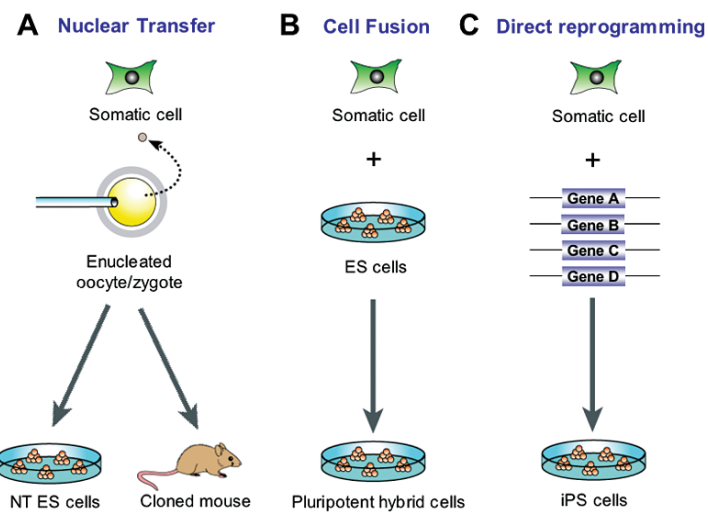

Figure 1. Different approaches for reprogramming somatic cells to pluripotency. $(A)$ Nuclear transfer (NT) involves injecting a somatic nucleus into an enucleated oocyte or zygote, resulting in the formation of cloned blastocysts, which can be transferred into recipient females to produce cloned mice ("reproductive cloning") or explanted in culture to derive NT ES cells for therapeutic purposes ("therapeutic cloning"). (B) Cell fusion between somatic cells and pluripotent cells generated hybrid cells, in which the somatic genome becomes reprogrammed by the pluripotent cell. (C) Direct or in vitro reprogramming requires ectopic expression of defined genes in somatic cells, which converts them into a pluripotent state. 
Cell-fusion experiments indicated that ES cells, like oocytes, must contain factors that mediate reprogramming to pluripotency and that these molecules should be identifiable to directly reprogram somatic cells into a pluripotent state (Fig. 1C). This notion prompted Yamanaka and colleagues to identify genes that are predominantly expressed in ES cells (Mitsui et al. 2003) and test the effect of their overexpression on somatic cells (Takahashi and Yamanaka 2006). Indeed, they identified four transcription factors, Oct4, Sox2, Klf4, and c-Myc, out of an initial group of 24 candidate genes, which when overexpressed in fibroblasts, gave rise to pluripotent cells called iPS cells (Fig. 2) (Takahashi and Yamanaka 2006). This chapter is aimed at summarizing the current knowledge on iPS cell research with an emphasis on work from our laboratory.

\section{TRANSCRIPTION-FACTOR-INDUCED REPROGRAMMING}

Previous work had indicated that individual transcription factors, when overexpressed or deleted, could induce cell-fate changes in somatic cells. Classical experiments in the 1980s showed that overexpression of the myogenic transcription factor MyoD was sufficient to convert fibroblasts into myogenic cells (Davis et al. 1987). Similarly, elimination of Pax 5 from B cells results in their dedifferentiation into progenitors that can give rise to multiple hematopoietic lineages (Nutt et al. 1999), and overexpression of the transcription factor CEBP $\alpha$ has been shown to reprogram $\mathrm{B}$ and $\mathrm{T}$ cells into macrophages (Xie et al. 2004; Laiosa et al. 2006). Together, these experiments provided the rationale for attempts to reprogram somatic cells directly into iPS cells.

iPS cells were initially obtained using drug selection for the ES-cell-specific, but nonessential, gene Fbx15

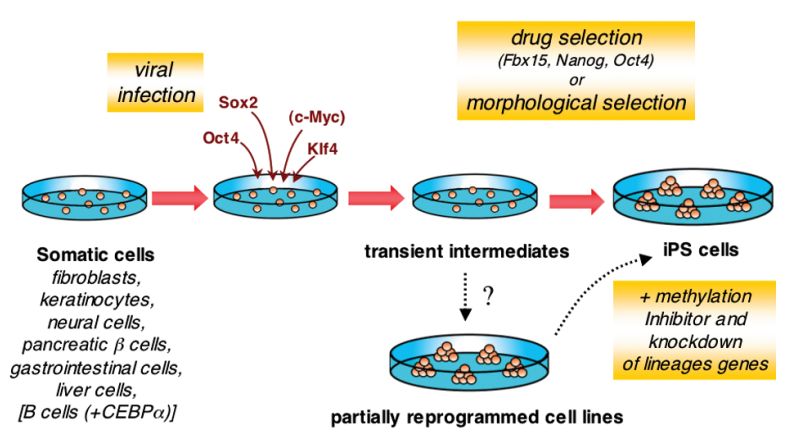

Figure 2. Direct reprogramming of somatic cells into induced pluripotent stem (iPS) cells. Flowchart of events involved in the direct reprogramming of somatic cells into iPS cells. Introduction of the Yamanaka factors into somatic cells results in the generation of iPS cells via defined intermediate steps. Drug selection or morphological criteria have been used to identify successfully reprogrammed colonies. Partially reprogrammed cell lines are thought to originate from transient intermediate cell populations and can be converted into iPS cells upon knockdown of lineage-specific genes and treatment with DNA methylation inhibitors. B lymphocytes could only be reprogrammed by additional overexpression of CEBP $\alpha$ and by use of a "secondary" system.
(Takahashi and Yamanaka 2006). These first-generation iPS cells were similar but not identical to ES cells. They appeared to be transcriptionally and epigenetically intermediate between ES cells and fibroblasts, and although they did give rise to teratomas, they could not support the development of viable mice. Subsequent studies, however, showed that identifying iPS cells based on drug selection for the ES-cell-specific genes Oct4 or Nanog (Maherali et al. 2007; Okita et al. 2007; Wernig et al. 2007), or simply based on morphological criteria alone (Blelloch et al. 2007; Maherali et al. 2007; Meissner et al. 2007), was sufficient to generate iPS cells that were highly similar to ES cells (Fig. 2). At the molecular level, iPS cells showed demethylation of the Oct4 and Nanog promoter regions and transcriptional patterns akin to ES cells (Maherali et al. 2007; Okita et al. 2007; Wernig et al. 2007). Global analysis of histone methylation patterns including histone H3 lysine 4 (K4) and H3 lysine 27 (K27) methylation indicated that iPS cells were indistinguishable from ES cells (Maherali et al. 2007). In addition, the somatically silenced $\mathrm{X}$ chromosome in female cells became reactivated and underwent random inactivation upon differentiation (Maherali et al. 2007), similar to ES cells derived by NT from female somatic cells (Eggan et al. 2000). At the functional level, iPS cells produced viable chimeras that showed contribution to the germ line (Maherali et al. 2007; Okita et al. 2007; Wernig et al. 2007) and even supported the development of fetuses that were derived entirely from iPS cells (Wernig et al. 2007; Hanna et al. 2008; Kim et al. 2008).

iPS cell have since been generated from multiple tissues, including blood, liver, stomach, pancreas, brain, skin, and adrenals (Fig. 2) (Aoi et al. 2008; Eminli et al. 2008; Hanna et al. 2008; Kim et al. 2008; Stadtfeld et al. 2008a; Wernig et al. 2008a). Moreover, human fibroblasts (Takahashi et al. 2007; Yu et al. 2007; Lowry et al. 2008; Maherali et al. 2008; Park et al. 2008b) and keratinocytes (Maherali et al. 2008) have been converted into iPS cells by the same or a different combination of factors including OCT4, SOX2, LIN28, and NANOG. These results suggest that in vitro reprogramming is a universal process that functions in cell types derived from all three germ layers and in different species. However, the mechanisms underlying reprogramming remain largely unknown.

\section{MOLECULAR CORNERSTONES OF DIRECT REPROGRAMMING}

In vitro reprogramming is a gradual process that takes between 1 and 2 weeks in murine fibroblasts to generate pluripotent cells from somatic cells (Takahashi and Yamanaka 2006; Maherali et al. 2007; Okita et al. 2007; Wernig et al. 2007). To dissect the mechanism of reprogramming, it has been informative to study partially reprogrammed cells that have failed to silence the retroviral transgenes and regain expression of many important pluripotency regulators. Partially reprogrammed cells may have been generated when Fbx15 selection was initially used to identify iPS cells (Takahashi and Yamanaka 2006) and are frequently obtained when morphological 


\section{INDUCED PLURIPOTENCY}

criteria are used to isolate iPS cells (Mikkelsen et al. 2008). These cell lines show incomplete demethylation and reactivation of pluripotency genes (Takahashi and Yamanaka 2006; Mikkelsen et al. 2008). Interestingly, genome-wide expression analyses showed that partially reprogrammed cell lines derived from B cells and fibroblasts are more similar to one another than to their cells of origin, suggesting that there could be one or several common intermediate state(s) in which somatic cells get trapped, irrespective of the cell of origin (see Fig. 2) (Mikkelsen et al. 2008).

Interestingly, partially reprogrammed cell lines show activation of lineage-specific genes not normally expressed in the starting cell population or in pluripotent cells (Mikkelsen et al. 2008). Knockdown of these genes, combined with the treatment with a DNA methylation inhibitor, resulted in a more efficient transition from the partially to a fully reprogrammed state, which suggests that ectopic expression of lineage-specific transcription factors and hypermethylation may prevent conversion into a pluripotent state (Fig. 2).

Although the analysis of partially reprogrammed cell states has been informative for understanding the "trapped" intermediate stages, a more detailed analysis of earlier and later stages of reprogramming will be critical for establishing the sequence of transcriptional and epigenetic events that lead to a pluripotent state. In attempts to define such early intermediates, two independent studies have shown that in vitro reprogramming of fibroblasts follows a defined sequence of molecular events, beginning with the down-regulation of somatic markers such as Thy 1 and collagens, followed by the reactivation of the embryonic marker SSEA1 (Fig. 3) (Brambrink et al. 2008; Stadtfeld et al. 2008b). SSEA1-positive cells then gradually reactivate other markers associated with pluripotency including Oct4, Sox2, Nanog, telomerase, and the silent X chromosome in female cells. Reactivation of these late markers correlates with the time window when cells become independent of viral transgene expression and enter a self-sustaining pluripotent state. Importantly, sort-

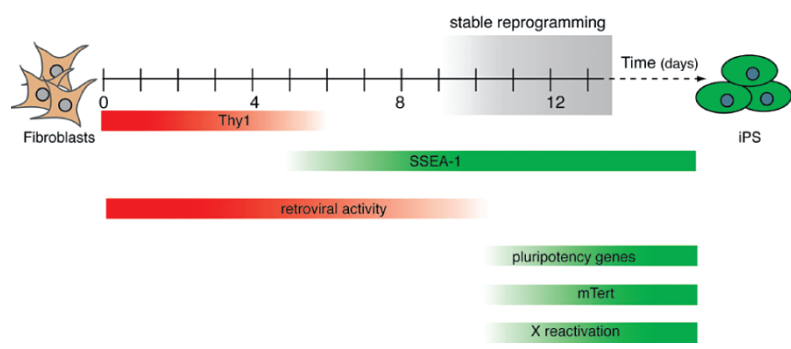

Figure 3. Molecular cornerstones of fibroblast into iPS cell reprogramming. Timescale of in vitro reprogramming into iPS cells with a summary of the major molecular events. (Gray box) Time window when cells convert into a pluripotent state and no longer depend on exogenous factor expression. (Red) Time frame of down-regulation of the fibroblast marker Thy1 and the silencing of retroviruses; (green) time frame of activation of the stem cell marker SSEA1 and other pluripotency associated events (reactivation of telomerase, pluripotency genes, and silent $\mathrm{X}$ chromosome in female cells). (Reprinted, with permission, from Stadtfeld et al. 2008b [C Cell Press].) ing and plating of these rare intermediate cell populations result in a significant increase in the number of successfully reprogrammed iPS colonies, thus validating the functional importance of the identified biomarkers (Stadtfeld et al. 2008b). The observation that somatic markers are downregulated before progressing into a pluripotent state further supports the notion that silencing of cell-type-specific programs is an important initial step toward reestablishing pluripotency. It also suggests that the differentiation state of the starting cell may affect the efficiency and kinetics of in vitro reprogramming.

\section{EFFECT OF CELL TYPE AND DIFFERENTIATION STATE ON REPROGRAMMING EFFICIENCY}

The derivation of iPS cells remains an extremely inefficient process ranging from $0.01 \%$ to $0.1 \%$. This low efficiency of iPS cell derivation may be due to rare cells within the starting population, which serve as selective cells of origin. For example, adult stem cells are present in many tissues at about the same frequency as the success rate of reprogramming. Consistent with this notion, NSCs have been suggested to give rise to iPS cells 30-50 times more efficiently than fibroblasts (Kim et al. 2008), although another report came to different conclusions (Eminli et al. 2008).

The identity of the starting cells that give rise to iPS cells remains controversial. Two recent experiments addressed the cell-of-origin question in different cellular systems and came to different conclusions. In the first set of experiments, Hanna et al. (2008) attempted reprogramming of B lymphocytes into iPS cells. B cells carry differentiation-associated DNA rearrangements, which serve as an unambiguous genetic marker for their differentiation state (Hochedlinger and Jaenisch 2002a). Interestingly, ectopic expression of Oct4, Sox2, c-Myc, and Klf4 alone was insufficient to reprogram B lymphocytes into iPS cells, even when using a "secondary" system, in which most, if not all, cells express the four factors homogeneously (Maherali et al. 2008; Wernig et al. 2008a). The authors had to either overexpress the transcription factor CEBP $\alpha$ or knock down its suppressed target gene Pax 5 in addition to overexpressing the four factors to generate iPS cells from B cells. In contrast, progenitor B cells (pro-B cells) were permissive for reprogramming by the four factors alone, consistent with the notion that the differentiation state of the starting cell may affect reprogramming efficiency. Although this experiment indicated that defined terminally differentiated cells remain susceptible for reprogramming by defined factors, it is unclear, at this point, whether the difficulty in reprogramming lymphocytes is due to a biological barrier or merely reflects technical limitations.

In another set of experiments, Stadtfeld et al. (2008a) used genetically marked, terminally differentiated pancreatic $\beta$ cells for reprogramming into iPS cells. $\beta$ cells gave rise to iPS cells at a frequency comparable to fibroblasts $(0.1-0.2 \%)$, demonstrating that this terminally differentiated cell type can be reprogrammed into iPS cells by just four factors and that adult stem cells are unlikely 
the selective cell type in successful reprogramming experiments. There are several explanations for the different outcomes of reprogramming lymphocytes and $\beta$ cells. First, lymphocytes belong to the mesodermal lineage, whereas $\beta$ cells are derived from endoderm. Liver and stomach cells, which are also endodermal derivatives, have recently been shown to be more amenable to reprogramming (Aoi et al. 2008) than fibroblasts (mesoderm). Alternatively, $\beta$ cells could be more easily reprogrammed than lymphocytes because the pancreas does not contain stem, progenitor, and differentiated cells, as seen in the hematopoietic system, but rather a pool of $\beta$ cells that continuously replicate (Dor et al. 2004). It will undoubtedly be interesting to compare the reprogramming efficiencies between undifferentiated and fully differentiated cells within a given cell lineage, for example, in the hematopoietic system.

\section{REPROGRAMMING AND INSERTIONAL MUTAGENESIS}

Another possible explanation for the low efficiency of reprogramming is the potential requirement for insertional mutagenesis by the viral transgenes (Hawley 2008). It has been previously shown that the retroviral infection of explanted blood stem cells selects for clones in which viruses inserted into genes conferring self-renewal to cells (Kustikova et al. 2005). Similarly, one or several of the viral copies present in iPS cells could have integrated into and activated a gene(s) that facilitates the reacquisition of a pluripotent, self-renewing state. The sequencing of 34 viral insertion sites in iPS cells derived from liver and stomach cells did not reveal any common integration sites (Aoi et al. 2008). However, sequencing has not yet been performed at saturation and it was still possible that insertional mutagenesis has a role during in vitro reprogramming (Hawley 2008). To ultimately exclude the possibility that there may be "hidden" reprogramming genes that become activated or inactivated as a result of viral integration, iPS cells needed to be generated without any genetic manipulation, for example, by using small chemical compounds, direct protein transduction, or nonintegrating viruses. Indeed, we have recently generated iPS cells without integrating viruses by infecting tail fibroblasts and hepatocytes with adenoviruses transciently expressing Oct4, Sox4, Kef4, and c-Myc (Stadtfeld et al. 2008).

\section{A HIGH EFFICIENCY SYSTEM TO STUDY THE MECHANISMS OF DIRECT REPROGRAMMING}

A third possibility for the low efficiency of reprogramming is the idea that the factors can only achieve reprogramming when expressed in precise relative amounts. Fibroblast-derived iPS cells carry on average 10-20 proviral transgenes expressing Oct4, Sox2, Klf4, and c$\mathrm{Myc}$, and the four transgenes are found at different copy numbers per cell (Takahashi and Yamanaka 2006; Maherali et al. 2007; Wernig et al. 2007; Eminli et al. 2008), suggesting that stoichiometry may be important.
This is consistent with observations in ES cells, where the levels of Oct 4 and Sox 2 are critical for maintaining a selfrenewing pluripotent state (Niwa et al. 2000; Kopp et al. 2008). In further agreement, the reprogramming of Sox2expressing NSCs into iPS cells in the absence of exogenous Sox 2 expression results in an approximately fourfold increase in overall efficiency (Eminli et al. 2008). Thus, it is conceivable that the frequency at which a single somatic cell receives the four viral transgenes at the appropriate stoichiometry is extremely low.

If viral infection is indeed the rate-limiting step, one would predict that cells that can reactivate all four factors at the correct stoichiometry should give rise to iPS cells at an efficiency close to $100 \%$. To address this question, we generated differentiated fibroblast-like "secondary" cells from human-induced pluripotent stem (hiPS) cells produced with doxycycline-inducible viral transgenes (Fig. 4) (Maherali et al. 2008). In these cells, most of the cells express the four factors together and likely at the correct stoichiometry upon exposure to doxycycline. Indeed, secondary hiPS cells were obtained up to 100 times more efficiently compared with iPS cells produced by direct viral infection, indicating that viral infection and the correct stoichiometry of the four factors are parameters that limit reprogramming efficiency. Experiments with mouse cells came to similar conclusions (Hanna et al. 2008; Wernig et al. 2008a). However, the overall efficiency was still quite low in all of these experiments (1-3\% for secondary cells compared with $0.01-0.1 \%$ for primary infected cells), suggesting that additional events need to take place in order to reprogram somatic cells to pluripotency. These events likely involve stochastic epigenetic alterations including changes in DNA and histone methylation. Consistent with this notion, the treatment of somatic cells with compounds that inhibit DNA or histone methylation or histone deacetylation enhances the recovery of iPS cells significantly (Meissner et al. 2007; Huangfu et al. 2008; Shi et al. 2008).

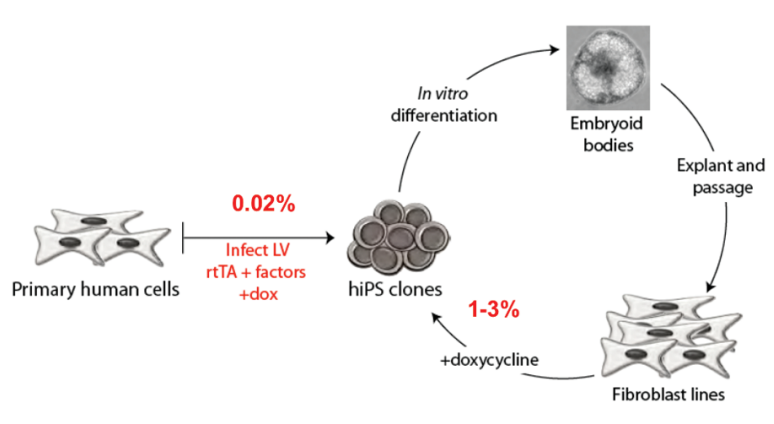

Figure 4. A high-efficiency system for the study of humaninduced pluripotency. Outline for the generation of "secondary cells" from hiPS cells. Infection of fibroblasts or keratinocytes with doxycycline-inducible lentiviruses (LV) and a reverse tetracycline trans-activator (rtTA) in the presence of doxycycline results in the formation of primary hiPS cells at low frequency $(\sim 0.02 \%)$. Upon differentiation of clonal hiPS cell lines into fibroblast-like cells in vitro, followed by exposure to doxycycline, secondary hiPS cells are generated at high frequency $(1-3 \%)$. The secondary system eliminates variability in infection rate efficiencies and factor expression and provides a platform for screening for drugs and genes that affect reprogramming. (Reprinted, with permission, from Maherali et al. 2008 [ $($ Cell Press].) 


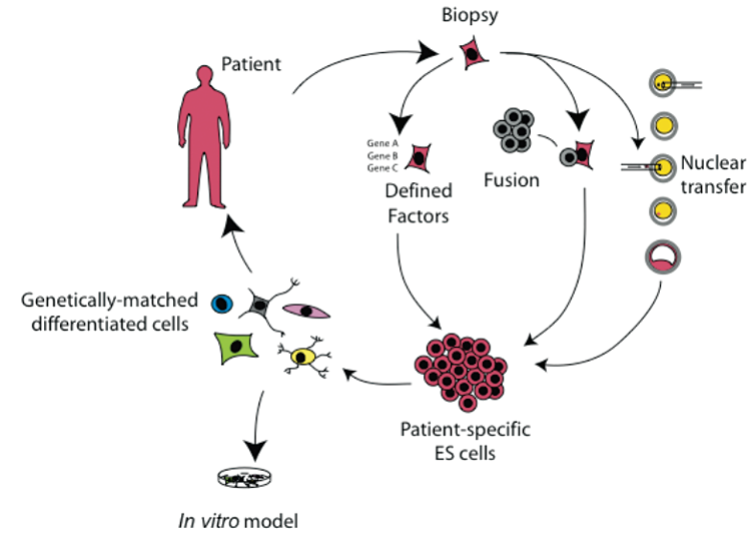

Figure 5. Therapeutic potential of reprogramming technology. Reprogramming by nuclear transfer, cell fusion, or defined factors may allow for the generation of patient-specific pluripotent cell lines. Pluripotent cells could be differentiated in vitro into the desired cell types and then transplanted into patients (cell therapy approach) or, alternatively, be used to establish in vitro models of diseases for drug screens and toxicology testing (disease modeling approach).

\section{CONCLUSIONS}

The study of induced pluripotency by defined transcription factors has yielded some important insights into the mechanisms underlying epigenetic reprogramming. Moreover, it has facilitated the derivation of patient-specific iPS cells from a variety of diseases (Dimos et al. 2008; Park et al. 2008a) to establish in vitro models for these disorders (Fig. 5). A major challenge before translating iPS technology into a therapeutic setting will be to induce pluripotency without genetic manipulation. Another open question is whether iPS cells are truly identical to ES cells or whether they retain a molecular memory of their cell of origin, as has been seen in some NT experiments (Hochedlinger and Jaenisch 2003). Finally, iPS technology has sparked interest in attempts to trans-differentiate specialized cells directly into other types of specialized cells by using alternative sets of transcription factors, for example from fibroblasts into myogenic cells (Davis et al. 1987), B lymphocytes into macrophages (Xie et al. 2004), or pancreatic exocrine cells into insulin-producing cells (Zhou et al. 2008). The next few years will undoubtedly bring exciting new discoveries on the role of transcription factors in cellular differentiation and epigenetic reprogramming.

\section{ACKNOWLEDGMENTS}

N.M. is supported by a graduate scholarship from the Natural Sciences and Engineering Research Council of Canada and a Sir James Lougheed Award from Alberta Scholarships. Support to K.H. is from the National Institutes of Health Director's Innovator Award, the Harvard Stem Cell Institute, the Kimmel Foundation, and the V Foundation. We thank members of the Hochedlinger lab for their scientific contributions and Chad Cowan for sharing graphic images.

\section{REFERENCES}

Aoi, T., Yae, K., Nakagawa, M., Ichisaka, T., Okita, K., Takahashi, K., Chiba, T., and Yamanaka, S. 2008. Generation of pluripotent stem cells from adult mouse liver and stomach cells. Science 321: 699-702

Blelloch, R., Venere, M., Yen, J., and Ramalho-Santos, M. 2007. Generation of induced pluripotent stem cells in the absence of selection. Cell Stem Cell 1: 245-247.

Brambrink, T., Hochedlinger, K., Bell, G., and Jaenisch, J. 2006. ES cells derived from cloned and fertilized blastocysts are transcriptionally and functionally indistinguishable. Proc. Natl. Acad. Sci. 103: 933-938.

Brambrink, T., Foreman, R., Welstead, G.G., Lengner, C.J., Wernig, M., Suh, H., and Jaenisch, R. 2008. Sequential expression of pluripotency markers during direct reprogramming of mouse somatic cells. Cell Stem Cell 2: 151-159.

Cowan, C.A., Atienza, J., Melton, D.A., and Eggan, K. 2005. Nuclear reprogramming of somatic cells after fusion with human embryonic stem cells. Science 309: 1369-1373.

Davis, R.L., Weintraub, H., and Lassar, A.B. 1987. Expression of a single transfected cDNA converts fibroblasts to myoblasts. Cell 51: 987-1000.

Dimos, J.T., Rodolfa, K.T., Niakan, K.K., Weisenthal, L.M., Mitsumoto, H., Chung, W., Croft, G.F., Saphier, G., Leibel, R., Goland, R., et al. 2008. Induced pluripotent stem cells generated from patients with ALS can be differentiated into motor neurons. Science 321: 1218-1221.

Dor, Y., Brown, J., Martinez, O.I., and Melton, D.A. 2004. Adult pancreatic $\beta$-cells are formed by self-duplication rather than stem-cell differentiation. Nature 429: 41-46.

Eggan, K., Akutsu, H., Hochedlinger, K., Rideout III, W., Yanagimachi, R., and Jaenisch, R. 2000. X-Chromosome inactivation in cloned mouse embryos. Science 290: 1578-1581.

Eminli, S., Utikal, J.S., Arnold, K., Jaenisch, R., and Hochedlinger, K. 2008. Reprogramming of neural progenitor cells into iPS cells in the absence of exogenous Sox 2 expression. Stem Cells (in press).

Fujiwara, T., Bandi, M., Nitta, M., Ivanova, E.V., Bronson R.T., and Pellman, D. 2005. Cytokinesis failure generating tetraploids promotes tumorigenesis in p53-null cells. Nature 437: 1043-1047.

Hanna, J., Wernig, M., Markoulaki, S., Sun, C.W., Meissner, A., Cassady, J.P., Beard, C., Brambrink, T., Wu, L.C., Townes, T.M., and Jaenisch, R. 2007. Treatment of sickle cell anemia mouse model with iPS cells generated from autologous skin. Science 318: 1920-1923.

Hanna, J., Markoulaki, S., Schorderet, P., Carey, B.W., Beard, C., Wernig M., Creyghton, M.P., Steine E.J., Cassady, J.P., Foreman, R., et al. 2008. Direct reprogramming of terminally differentiated mature B lymphocytes to pluripotency. Cell 133: 250-264.

Hawley, R.G. 2008. Does retroviral insertional mutagenesis play a role in the generation of induced pluripotent stem cells? Mol. Ther. 16: 1354-1355.

Hochedlinger, K. and Jaenisch, R. 2002a. Monoclonal mice generated by nuclear transfer from mature B and T donor cells. Nature 415: 1035-1038.

Hochedlinger, K. and Jaenisch, R. 2002b. Nuclear transplantation: Lessons from frogs and mice. Curr. Opin. Cell Biol. 14: $741-748$.

Hochedlinger, K. and Jaenisch, R. 2003. Nuclear transplantation, embryonic stem cells, and the potential for cell therapy. N. Engl. J. Med. 349: 275-286

Huangfu, D., Maehr, R., Guo, W., Eijkelenboom, A., Snitow, M., Chen A.E., and Melton, D.A. 2008. Induction of pluripotent stem cells by defined factors is greatly improved by small-molecule compounds. Nat. Biotechnol. 26: 795-797.

Kim, J.B., Zaehres, H., Wu, G., Gentile, L., Ko, K., Sebastiano, V., Arauzo-Bravo, M.J., Ruau, D., Han, D.W., Zenke, M., and Scholer, H.R. 2008. Pluripotent stem cells induced from adult neural stem cells by reprogramming with two factors. Nature 454: $646-650$

Kopp, J.L., Ormsbee, B.D., Desler, M., and Rizzino, A. 2008. Small increases in the level of Sox 2 trigger the differentiation 
of mouse embryonic stem cells. Stem Cells 26: 903-911.

Kustikova, O., Fehse, B., Modlich, U., Yang, M., Dullmann, J. Kamino, K., von Neuhoff, N., Schlegelberger, B., Li, Z., and Baum, C. 2005. Clonal dominance of hematopoietic stem cells triggered by retroviral gene marking. Science 308: $1171-1174$.

Laiosa, C.V., Stadtfeld, M., Xie, H., de Andres-Aguayo, L., and Graf, T. 2006. Reprogramming of committed T cell progenitors to macrophages and dendritic cells by $\mathrm{C} / \mathrm{EBP} \alpha$ and PU.1 transcription factors. Immunity 25: 731-744.

Lowry, W.E., Richter, L., Yachechko, R., Pyle, A.D., Tchieu, J., Sridharan, R., Clark, A.T., and Plath, K. 2008. Generation of human induced pluripotent stem cells from dermal fibroblasts. Proc. Natl. Acad. Sci. 105: 2883-2888.

Maherali, N., Sridharan, R., Xie, W., Utikal, J., Eminli, S., Arnold, K., Stadtfeld, M., Yachechko, R., Tchieu, J., Jaenisch, R., Plath, K., and Hochedlinger, K. 2007. Directly reprogrammed fibroblasts show global epigenetic reprogramming and widespread tissue contribution. Cell Stem Cell 1: 55-70.

Maherali, N., Ahfeldt, T., Rigamonti, A., Utikal, J., Cowan, C.A., and Hochedlinger, K. 2008. A high-efficiency system for the generation and study of human induced pluripotent stem cells. Cell Stem Cell 3: 340-345.

Meissner, A., Wernig, M., and Jaenisch, R. 2007. Direct reprogramming of genetically unmodified fibroblasts into pluripotent stem cells. Nat. Biotechnol. 25: 1177-1181.

Mikkelsen, T.S., Hanna, J., Zhang, X., Ku, M., Wernig, M., Schorderet, P., Bernstein, B.E., Jaenisch, R., Lander, E.S., and Meissner, A. 2008. Dissecting direct reprogramming through integrative genomic analysis. Nature 454: 794

Mitsui, K., Tokuzawa, Y., Itoh, H., Segawa, K., Murakami, M., Takahashi, K., Maruyama, M., Maeda, M., and Yamanaka, S. 2003. The homeoprotein Nanog is required for maintenance of pluripotency in mouse epiblast and ES cells. Cell 113: 631-642

Niwa, H., Miyazaki, J., and Smith, A.G. 2000. Quantitative expression of Oct-3/4 defines differentiation, dedifferentiation or self-renewal of ES cells. Nat. Genet. 24: 372-376.

Nutt, S.L., Heavey, B., Rolink, A.G., and Busslinger, M. 1999. Commitment to the B-lymphoid lineage depends on the transcription factor Pax5. Nature 401: 556-562.

Okita, K., Ichisaka, T., and Yamanaka, S. 2007. Generation of germline-competent induced pluripotent stem cells. Nature 448: $313-317$.

Park, I.H., Arora, N., Huo, H., Maherali, N., Ahfeldt, T., Shimamura, A., Lensch, M.W., Cowan, C., Hochedlinger, K., and Daley, G.Q. 2008a. Disease-specific induced pluripotent stem cells. Cell 134: 877-886.

Park, I.H., Zhao, R., West, J.A., Yabuuchi, A., Huo, H., Ince, T.A., Lerou, P.H., Lensch, M.W., and Daley, G.Q. 2008b. Reprogramming of human somatic cells to pluripotency with defined factors. Nature 451: 141-146.

Rideout III, W.M., Hochedlinger, K., Kyba, M., Daley, G.Q., and Jaenisch, R. 2002. Correction of a genetic defect by nuclear transplantation and combined cell and gene therapy. Cell 109: 17-27.

Shi, Y., Do, J.T., Desponts, C., Hahm, H.S., Scholer, H.R., and
Ding, S. 2008. A combined chemical and genetic approach for the generation of induced pluripotent stem cells. Cell Stem Cell 2: $525-528$

Silva, J., Chambers, I., Pollard, S., and Smith, A. 2006. Nanog promotes transfer of pluripotency after cell fusion. Nature 441: 997-1001.

Stadtfeld, M., Brennand, K., and Hochedlinger, K. 2008a. Reprogramming of pancreatic $\beta$ cells into induced pluripotent stem cells. Curr. Biol. 18: 890-894.

Stadtfeld, M., Maherali, N., Breault, D.T., and Hochedlinger, K. 2008b. Defining molecular cornerstones during fibroblast to iPS cell reprogramming in mouse. Cell Stem Cell 2: 230-240.

Stadtfeld, M., Nagaya, M., Utikal, J., Weir, G., and Hochedlinger, K. 2008. Induced pluripotent stem cells generated without viral integration. Science (in press).

Tada, M., Takahama, Y., Abe, K., Nakatsuji, N., and Tada, T. 2001. Nuclear reprogramming of somatic cells by in vitro hybridization with ES cells. Curr. Biol. 11: 1553-1558.

Takahashi, K. and Yamanaka, S. 2006. Induction of pluripotent stem cells from mouse embryonic and adult fibroblast cultures by defined factors. Cell 126: 663-676.

Takahashi, K., Tanabe, K., Ohnuki, M., Narita, M., Ichisaka, T., Tomoda, K., and Yamanaka, S. 2007. Induction of pluripotent stem cells from adult human fibroblasts by defined factors. Cell 131: 861-872.

Wakayama, T., Perry, A.C., Zuccotti, M., Johnson, K.R., and Yanagimachi, R. 1998. Full-term development of mice from enucleated oocytes injected with cumulus cell nuclei. Nature 394: 369-374.

Wernig, M., Meissner, A., Foreman, R., Brambrink, T., Ku, M., Hochedlinger, K., Bernstein, B.E., and Jaenisch, R. 2007. In vitro reprogramming of fibroblasts into a pluripotent ES-celllike state. Nature 448: 318-324.

Wernig, M., Lengner, C.J., Hanna, J., Lodato, M.A., Steine, E.J., Foreman, R., Staerk, J., Markoulaki, S., and Jaenisch, R. 2008a. A drug-inducible transgenic system for direct reprogramming of multiple somatic cell types. Nat. Biotechnol. 26: 916-924.

Wernig, M., Zhao, J.P., Pruszak, J., Hedlund, E., Fu, D., Soldner, F., Broccoli, V., Constantine-Paton, M., Isacson, O., and Jaenisch, R. 2008b. Neurons derived from reprogrammed fibroblasts functionally integrate into the fetal brain and improve symptoms of rats with Parkinson's disease. Proc. Natl. Acad. Sci. 105: 5856-5861.

Wilmut, I., Schnieke, A.E., McWhir, J., Kind, A.J., and Campbell, K.H. 1997. Viable offspring derived from fetal and adult mammalian cells. Nature 385: 810-813.

Xie, H., Ye, M., Feng, R., and Graf, T. 2004. Stepwise reprogramming of B cells into macrophages. Cell 117: 663-676.

Yu, J., Vodyanik, M.A., Smuga-Otto, K., Antosiewicz-Bourget, J., Frane, J.L., Tian, S., Nie, J., Jonsdottir, G.A., Ruotti, V., Stewart, R., Slukvin, I.I., and Thomson, J.A. 2007. Induced pluripotent stem cell lines derived from human somatic cells. Science 318: 1917-1920.

Zhou, Q., Brown, J., Kanarek, A., Rajagopal, J., and Melton, D.A. 2008. In vivo reprogramming of adult pancreatic exocrine cells to $\beta$-cells. Nature 455: 627-632. 


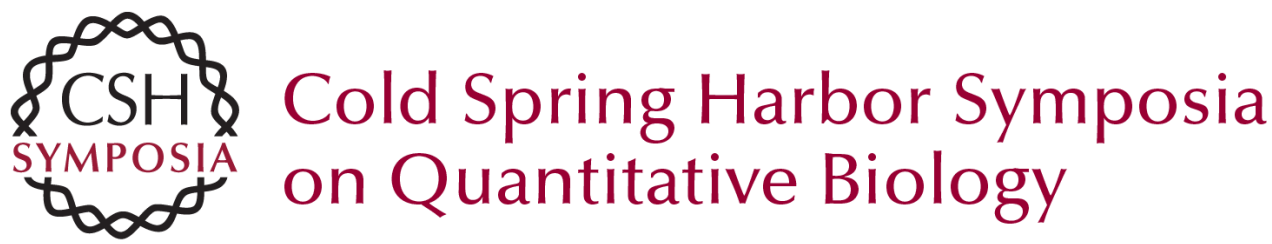

\section{Induced Pluripotency of Mouse and Human Somatic Cells}

N. Maherali and K. Hochedlinger

Cold Spring Harb Symp Quant Biol 2008 73: 157-162 originally published online November 6, 2008 Access the most recent version at doi:10.1101/sqb.2008.73.017

References This article cites 48 articles, 10 of which can be accessed free at: http://symposium.cshlp.org/content/73/157.full.html\#ref-list-1

License

Email Alerting Receive free email alerts when new articles cite this article - sign up in the Service box at the top right corner of the article or click here. 